(c) American Dairy Science Association, 2006.

\title{
Random Regression Models for Male and Female Fertility Evaluation Using Longitudinal Binary Data
}

\author{
T. Averill, ${ }^{*}$ R. Rekaya,$\dagger^{1}$ and K. Weigelł \\ *National Agriculture Statistics Service, USDA, Concord, NH 03302-1444 \\ †Department of Animal \& Dairy Science, The University of Georgia, Athens 30602-2771 \\ ‡Department of Dairy Science, University of Wisconsin-Madison 53706-1284
}

\section{ABSTRACT}

A longitudinal Bayesian threshold analysis of insemination outcomes was carried out using 2 random regression models with 3 (Model 1) and 5 (Model 2) parameters to model the additive genetic values at the liability scale. All insemination events of first-parity Holstein cows were used. The outcome of an insemination event was treated as a binary response of either a success (1) or a failure (0). Thus, all breeding information for a cow, including all service sires, was included, thereby allowing for a joint evaluation of male and female fertility. An edited data set of 369,353 insemination records from 210,373 first-lactation cows was used. On the liability scale, both models included the systematic effects of herd-year, month of insemination, technician, and regressions on age of service sire and milk yield during the first $100 \mathrm{~d}$ of lactation. The random effects in the model were the 3 or 5 random regression coefficients specific to each cow, the permanent effect of the cow, and the service sire effect. Using Model 1, the estimated heritability of an insemination outcome decreased from 0.035 at $d 50$ to 0.032 at $d 140$ and then increased continuously with DIM. The genetic correlations for insemination success at different time points ranged from 0.83 to 0.99 , and their magnitude decreased with an increase in the interval between inseminations. A similar trend was observed for heritability and genetic correlations using Model 2. However, the average estimate of heritability was much higher (0.058) than those obtained using Model 1 or a repeatability model. In addition, the estimated genetic correlations followed the same trend as Model 1, but were lower and with a higher rate of decrease when the interval between inseminations increased. The posterior mean of service sire variance was 0.01 for both models, and permanent environmental variance was 0.05 and 0.02 for Models 1 and 2, respectively. Model comparison based on the

Received July 11, 2005.

Accepted January 31, 2006.

${ }^{1}$ Corresponding author: rrekaya@uga.edu
Bayes factor indicated that Model 1 was more plausible, given the data.

Key words: longitudinal binary data, random regression, fertility, dairy cow

\section{INTRODUCTION}

In the last 3 decades, the dairy industry in the United States has experienced substantial changes. Royal et al. (2000) reported that in $20 \mathrm{yr}$ (1975-1997) conception rates in Holstein cows had decreased by $0.45 \%$ per year (Butler and Smith, 1989; Beam and Butler, 1999). The decrease in fertility can be partially attributed to unfavorable genetic relationships between fertility and production traits (Freeman, 1984; Ranberg et al., 2003). Although several traits are being used for genetic evaluation of reproductive performance, the outcome of an insemination event seems to be the trait of choice, because it is measured early in the breeding season and hence has less environmental influence (Averill et al., 2004). Similar to many other reproductive traits, the outcome of an insemination event depends on both male and female fertility.

Although some attempts have recently been made to jointly analyze male and female fertility (Jamrozik et al., 2005), these 2 traits have been analyzed separately in the majority of cases. Further, not all insemination events during a breeding season are being considered. In fact, traits such as outcome of first insemination, based on the nonreturn rate or conception rate, use only one record per cow within lactation. Thus, additional breeding records of cows having more than one insemination are not considered, leading to information loss. With one record per cow, information about male fertility in second and later services is also lost. Consequently, the resulting service sire effects and female fertility could be biased. To account properly for service sire effect and female fertility in a joint analysis, all insemination events could be considered, such as by using a longitudinal threshold model.

In dairy cattle, random regression models have primarily been used to analyze production traits (Marti and Funk, 1994; Veerkamp and Goddard, 1998; Swalve, 
2000; Jensen, 2001) and health-related traits such as mastitis (Kadarmideen et al., 2000; Heringstad et al., 2001; Heringstad et al., 2003; Rekaya et al., 2003). Several random coefficient models, including random regression and splines, have been implemented and compared (White et al., 1999; Pool et al., 2000). The basic idea underlying all these models consists of modeling the additive genetic values (or other random effects in the model) as a function of an observed dependent variable (i.e., time, weight) through a set of random coefficients. Compared with cross-sectional models, the theoretical and biological advantages of using random regression-based models for longitudinal data are numerous and have been reported extensively in the literature (Meyer, 1998; Huisman et al., 2002).

Kirkpatrick and Heckman (1989), among others, have discussed using longitudinal models for the analysis of infinite-dimensional characters. Using dairy cattle data, Rekaya et al. (1998) have applied a longitudinal threshold model for the analysis of sequential binary responses. Further, Veerkamp et al. (2001) have used a longitudinal binary approach to analyze censored survival data via random regression models. In addition to the advantages of using the random regression model for continuous data, longitudinal threshold models offer the possibility of computing quantities of interest to animal breeders that could not be obtained using cross-sectional analyses, such as the probability of observing a success or failure within a specific period. Heringstad et al. (2001) applied the proposed model to analyze the incidence of mastitis in the Norwegian Red dairy cattle population. The estimated heritability ranged from 0.01 to 0.18 , with the maximum being by the middle of the lactation. Furthermore, quantities were developed, including the expected number of mastitis episodes per lactation, the expected number of days without mastitis, and the probability of having at least one mastitis episode during a given period of time, and were used as alternatives to a single breeding value for sire selection. Kadarmideen et al. (2001) used a similar approach to analyze mastitis data in the UK Holstein population. Jakobsen et al. (2003) used a bivariate longitudinal threshold-continuous model for analysis of health and production traits in the Danish dairy population. Their model yielded interesting results, such as a description of the susceptibility to diseases as a function of the shape of the lactation curve and the relationships among timing and level of peak milk production and the incidence of mastitis.

In this study, the repeatability threshold model proposed by Averill et al. (2004) for analyzing insemination outcomes in first lactation, where all insemination events of a cow in a breeding season were considered as repeated measurements, is extended via a random coefficient-based model with specific objectives: 1) to use all available breeding information for joint evaluation of male and female fertility; 2) to implement and compare 2 random coefficient functions for modeling the additive breeding value using Bayes factors; and 3) to develop new selection criteria other than the single breeding value.

\section{MATERIALS AND METHODS}

The data consisted of insemination records from firstparity dairy cows generated between 2002 and 2003, provided by AgriTech Analytics (Visalia, CA). The trait of interest was the outcome of all insemination events, where 1 was defined as a successful insemination event and 0 was defined as an unsuccessful (failed) insemination event. Data editing consisted of keeping herd-year contemporary groups and technicians with at least 5 and 10 records, respectively. All extreme-case problem classes for contemporary groups and technicians were removed. Further, cows with inconsistent identification, more than one successful insemination per lactation, or an unrealistic interval between consecutive inseminations were removed. After editing, the data consisted of a total of 210,373 cows with 369,353 records, averaging 1.76 inseminations per cow. The data also included a total of 1,582 technicians, 3,210 service sires, and 967 herd-year contemporary groups.

The pedigree had a high proportion of missing or unknown sires because of the high percentage of cows in California with missing sire identification. After matching the identification numbers in the data and pedigree files provided by AgriTech Analytics with sire pedigrees from the National Association Animal Breeders, international sire identification numbers were determined and used in building the pedigree. The pedigree file consisted of 218,706 animals.

Before describing the longitudinal setting, a basic latent variable model for a cross-sectional binary response is described. Assume the observed binary response, $y_{i}$, is related to a continuous underlying variable $l_{i}$ satisfying the following condition:

$$
y_{i}= \begin{cases}1 & \text { if } l_{i}>T \\ 0 & \text { if } l_{i} \leq T\end{cases}
$$

where $l_{i} \sim N\left(\mu_{i}, \sigma_{e}^{2}\right)$ and $T$ is a threshold value. The probability of observing a successful insemination (i.e., $\left.y_{i}=1\right)$ is

$$
\begin{aligned}
P_{i}=\operatorname{pr}\left(l_{i}>T \mid \mu_{i}\right) & =1-p r\left(l_{i} \leq T \mid \mu_{i}\right) \\
& =1-\Phi\left(\frac{\left.\mathrm{T}-\mu_{i}\right)}{\sigma_{e}}\right),
\end{aligned}
$$


where $\Phi$ is the cumulative standard normal distribution function. As such, the model is not identifiable and $\mu_{i}$, $T$, and $\sigma_{e}^{2}$ cannot be inferred separately. Thus, at least 2 restrictions are needed. In this study, $T$ and $\sigma_{e}^{2}$ were set to zero and one, respectively, leading to

$$
P_{i}=\operatorname{pr}\left(l_{i}>T \mid \mu_{i}\right)=1-\Phi\left(-\mu_{i}\right)=\Phi\left(\mu_{i}\right) .
$$

Furthermore, $\mu_{i}$ can be linearly related to a set of systematic and random effects as

$$
\mu_{i}=\mathbf{x}_{i} \boldsymbol{\beta}+\mathbf{z}_{i} \mathbf{u},
$$

where $\mathbf{x}_{i}$ and $\mathbf{z}_{i}$ are known incidence row vectors, and $\boldsymbol{\beta}$ and $\mathbf{u}$ are unknown location parameters corresponding to systematic and random effects, respectively.

The implementation of this model in a Bayesian analysis using data augmentation became feasible after the research of Albert and Chib (1993) and Sorensen et al. (1995). All pertinent posterior distributions needed for Bayesian implementation via Markov chain Monte Carlo methods are in closed form.

In a longitudinal situation, let $y_{i}=\left(y_{i t_{1}}, y_{i t_{2}}, \ldots, y_{i t_{n_{i}}}\right)^{\prime}$ be an $n_{i} \times 1$ vector of binary responses for animal $i(i=$ $1,2, \ldots, q)$ observed at times $t_{1}, t_{2}, \ldots, t_{n_{i}}$, where $n_{i}$ is the number of inseminations for animal $i$. As in the case of the cross-sectional analysis, the binary response observed at time $t_{j}$ is related to a normally distributed underlying variable satisfying [1]:

$$
l_{i j} \sim N\left(\mu_{i j}, 1\right),
$$

where $\mu_{i j}$ is now a function of time. In this study, 2 functional forms were used to model $\mu_{i j}$. Although the choice of these 2 functions was arbitrary, our main selection criteria were based on the number of parameters and the availability of computer software to implement the analyses. It is worth mentioning that orthogonal polynomials and even splines could have been used to model the $\mu_{i j}$. However, the unavailability of computer software to implement a longitudinal binary analysis has precluded their use in this study.

\section{Quadratic Linear Function (Model 1)}

A quadratic regression on the time elapsed between calving and insemination date was used to model the additive breeding value of the inseminated cow. Thus,

$$
\mu_{i j k m}=\text { fixed }+a_{0 i}+a_{1 i} z_{i j}+a_{2 i} z_{i j}^{2}+s_{k}+p_{i}
$$

where $\mu_{i j k m}$ is the conditional mean for cow $i$ at time $j$; fixed is the fixed effects of herd-year of calving, techni- cian, month of insemination, regression on age of service sire, and regression on milk yield in the first 100 $\mathrm{d}$ of lactation; $\mathbf{u}_{i}=\left[\begin{array}{lll}a_{i 0} & a_{i 1} & a_{i 2}\end{array}\right]$ is a $3 \times 1$ vector of random regressions specific to cow $i ; s_{k}$ is the random effect of service sire $k$ (without relationships between service sires); $p_{i}$ is the random permanent environmental effect particular to all $n_{i}$ records of cow $i$; and $z_{i j}=$ number of DIM for cow $i / 365$ is specific for cow $i$ at time $j$.

\section{Ali-Schaeffer Function (Model 2)}

This 5-parameter function was used to model the additive genetic values of the inseminated cows (Ali and Schaeffer, 1987). Thus,

$$
\begin{gathered}
\mu_{i j k m}=\text { fixed }+a_{i 0}+a_{i 1} z_{i j}+a_{i 2} z_{i j}^{2} \\
+a_{i 3} \ln \left(z_{i j}^{-1}\right)+a_{i 4}\left[\ln \left(z_{i j}^{-1}\right)\right]^{2}+s_{k}+p_{i}
\end{gathered}
$$

where $\mu_{i j k m}$, fixed, $s_{k}$, and $p_{i}$ are as before, and $\mathbf{u}_{i}=$ $\left[\begin{array}{lllll}a_{i 0} & a_{i 1} & a_{i 2} & a_{i 3} & a_{i 4}\end{array}\right]$ is a $5 \times 1$ vector of the random regression coefficient specific to cow $i$.

Milk yield in the first $100 \mathrm{~d}$ was included as a covariate to account for the recursive relationship between fertility and early milk production. Although these 2 traits have some genetic correlation between them, that was not accounted for appropriately in the univariate analyses implemented in this study; the inclusion of early milk production as a covariate will help account for the environmental correlation and recursive relationship between the 2 traits. Although random regression modeling is more appropriate for the permanent effect, given the expected change over time, it was assumed to be constant because random regressions with 2 and 4 parameters for this effect showed major convergence problems in preliminary tests. This could have been due in part to the small number of records per cow.

To complete the Bayesian implementation, prior distributions for all unknown parameters in the model have to be specified. It was assumed that:

$$
\begin{gathered}
p(\beta) \sim U\left[\beta_{\min }, \beta_{\max }\right] ; \\
p\left(\mathbf{u} \mid \mathbf{G}_{0}\right) \sim N\left(\mathbf{0}, \mathbf{A} \otimes \mathbf{G}_{0}\right) ; \\
p\left(\mathbf{p} \mid \sigma_{p}^{2}\right) \sim N\left(\mathbf{0}, \mathbf{I} \sigma_{p}^{2}\right) ; \\
p\left(\mathbf{s} \mid \sigma_{s}^{2}\right) \sim N\left(\mathbf{0}, \mathbf{I} \sigma_{s}^{2}\right) ; \\
p\left(\sigma_{s}^{2}\right) \sim U[0,1] ;
\end{gathered}
$$

and

$$
p\left(\sigma_{p}^{2}\right) \sim U[0,1],
$$

Journal of Dairy Science Vol. 89 No. 9, 2006 
where $\mathbf{G}_{0}$ is a $3 \times 3$ and $5 \times 5$ genetic (co)variance matrix for Models 1 and 2 , respectively, $U[0,1]$ is the uniform distribution, $\mathbf{A}$ is the additive relationship matrix, and $\beta_{\min }$ and $\beta_{\max }$ were set to -100 and 100 , respectively.

The vector of unknown parameters was augmented with the liabilities suggested by Sorensen et al. (1995). The resulting joint posterior distribution and the conditional distributions needed for the implementation of the Gibbs sampler were in closed form, being normal for the systematic and random effects, truncated normal for the liabilities, scaled inverted Wishart for $\mathbf{G}_{0}$, and scaled inverted $\chi^{2}$ for $\sigma_{s}^{2}$ and $\sigma_{p}^{2}$. For both models, and based on a convergence analysis and visual inspection, a unique chain of 75,000 iterations was implemented, with a burn-in period of 25,000 iterations.

The Bayes factor, as defined by Newton and Raftery (1994), was used to assess the plausibility of the postulated models. The marginal density of the data under each of the models was estimated from the harmonic means of likelihood values evaluated at the posterior draws such that

$$
\hat{p}\left(\mathbf{y} \mid \mathrm{M}_{i}\right)=\left\{\frac{1}{N} \sum_{k=1}^{N}\left[p\left(\mathbf{y} \mid \boldsymbol{\theta}^{(k)}, \mathrm{M}_{i}\right]^{-1}\right\}^{-1}\right.
$$

where $\mathbf{y}$ is the vector of observed binary responses and $\theta^{(k)}$ is the $k$ th Gibbs sample of parameters under model $\mathbf{M}_{i}$. The estimated Bayes factor between models $\mathrm{M}_{i}$ and $\mathrm{M}_{j}$ is:

$$
\mathrm{B}_{\mathrm{M}_{i}, \mathrm{M}_{j}}=\frac{\hat{p}\left(\mathbf{y} \mid \mathrm{M}_{i}\right)}{\hat{p}\left(\mathbf{y} \mid \mathrm{M}_{j}\right)^{\prime}}
$$

\section{Genetic (Co)variances and Heritabilities}

The genetic (co)variances and heritabilities of success or failure of insemination at the liability scale are a function of time and can be obtained easily. For Model 1 , the genetic covariance, on the liability scale, between success and failure of inseminations at times $t_{i}$ and $t_{j}$ is given by

$$
\operatorname{cov}\left(t_{i}, t_{j}\right)=\mathbf{V}^{\prime}\left(t_{i}\right) \mathbf{G}_{0} \mathbf{V}\left(t_{j}\right)
$$

where $\mathbf{G}_{0}$ is a $3 \times 3$ genetic (co)variance matrix for the random regression parameters and

$$
\mathbf{V}^{\prime}\left(t_{i}\right)=\left[\begin{array}{lll}
1 & z_{i t_{\mathrm{i}}} & z_{i t_{\mathrm{i}}}^{2}
\end{array}\right]
$$

Similarly, for Model 2 the genetic covariance is given by

$$
\operatorname{cov}\left(t_{i}, t_{j}\right)=\mathbf{W}^{\prime}\left(t_{i}\right) \mathbf{G}_{0} \mathrm{~W}\left(t_{j}\right)
$$

where $\mathbf{G}_{0}$ is a $5 \times 5$ genetic (co)variance matrix and

$$
\mathbf{W}^{\prime}\left(t_{i}\right)=\left[\begin{array}{llll}
1 & z_{i t_{\mathrm{i}}} & z_{i t_{\mathrm{i}}}^{2} & \left.\ln \left(z_{i t_{\mathrm{i}}}^{-1}\right) \ln z_{i t_{\mathrm{i}}}^{-1}\right)^{2}
\end{array}\right]
$$

Heritabilities on the liability scale at time $t$ are defined as

$$
h_{t}^{2}=\frac{\mathbf{V}^{\prime}(t) \mathbf{G}_{0} \mathbf{V}(t)}{\mathbf{V}^{\prime}(t) \mathbf{G}_{0} \mathbf{V}(t)+\sigma_{s}^{2}+\sigma_{p}^{2}+1}
$$

for Model 1 and

$$
h_{t}^{2}=\frac{\mathbf{W}^{\prime}(t) \mathbf{G}_{0} \mathbf{W}(t)}{\mathbf{W}^{\prime}(t) \mathbf{G}_{0} \mathbf{W}(t)+\sigma_{s}^{2}+\sigma_{p}^{2}+1}
$$

for Model 2.

Bayesian analysis of longitudinal binary data via Markov chain Monte Carlo techniques allows a straightforward calculation of quantities of interest for selection decisions. In fact, criteria such as the probability of conception after first insemination, probability of conception within $365 \mathrm{~d}$, probability of no conception within $365 \mathrm{~d}$, and probability of no conception in the first 3 inseminations are computed as by-products of the sampling process and can be used together with the EBV for making breeding decisions. The following selection criteria were computed in this study:

a) probability of conception after first insemination within $75 \mathrm{~d}$ :

$$
p\left(y_{i 75}=1\right)=1-p\left(y_{i 75}=0\right)=\Phi\left(\mu_{i 75}\right) ;
$$

b) probability of conception within $365 \mathrm{~d}$ :

$$
p_{i}(1)=1-\prod_{j=1}^{n_{i}}\left[1-\Phi\left(\mu_{i j}\right)\right] ;
$$

c) probability of no conception within $365 \mathrm{~d}$ :

$$
p_{i}(0)=1-p_{i}(1)
$$

d) probability of no conception in the first 3 inseminations $\left(t_{j}=75, t_{j}=96\right.$, and $\left.t_{j}=117\right)$ :

$$
\begin{gathered}
p\left(y_{i 75}=0, y_{i 96}=0, y_{i 117}=0\right)= \\
p\left(y_{i 75}=0\right) \cdot p\left(y_{i 96}=0\right) \cdot p\left(y_{i 117}=0\right) .
\end{gathered}
$$

The probabilities in a) to d) were calculated assuming a population average derived based on the percentage of successful inseminations in the data set. For an observed insemination success rate of $37 \%$, the population mean was set as equal to -0.33 . The probabilities in a) 
Table 1. Summary of the posterior distribution for genetic (co)variances, service sire variance, and permanent environment variance using Model 1

\begin{tabular}{lrlrr}
\hline Component $^{1}$ & \multicolumn{1}{c}{ Mean } & SD & \multicolumn{2}{c}{ HPD, 95\% } \\
\hline$g_{00}$ & 0.0422 & 0.0049 & 0.0329 & 0.0506 \\
$g_{11}$ & 0.0294 & 0.0065 & 0.0187 & 0.0455 \\
$g_{22}$ & 0.0010 & 0.0002 & 0.0008 & 0.0013 \\
$g_{01}$ & -0.0169 & 0.0009 & -0.0031 & -0.0004 \\
$g_{01}$ & 0.0056 & 0.0006 & 0.0044 & 0.0067 \\
$g_{12}$ & -0.0013 & 0.0001 & -0.0003 & $8.5 \mathrm{E}-6$ \\
$\sigma_{p}^{2}$ & 0.0519 & 0.0294 & 0.0122 & 0.1009 \\
$\sigma_{s}^{2}$ & 0.0101 & 0.0012 & 0.0078 & 0.0125 \\
\hline
\end{tabular}

${ }^{1} g_{i j}$ is the genetic (co)variance between random coefficients $i$ and $j ; \sigma_{s}^{2}$ is the service sire variance; and $\sigma_{p}^{2}$ is the permanent environment variance.

to d) were then calculated from the cumulative distribution function of a normal distribution with mean equal to the sum of the population mean $(-0.33)$ and the cow's breeding and permanent effects. For cows with only one record, for which the permanent effect could not be calculated, their permanent effects were set to zero. It is worth mentioning that these probabilities in a) to d) change in a nonlinear manner with a change in the population mean.

\section{RESULTS AND DISCUSSION}

\section{Model 1}

A summary of the posterior distributions of the genetic (co)variances, permanent variances, and service sire variances for Model 1 is presented in Table 1 . The intercept (first parameter of the quadratic function; $g_{00}$ ) explained more than $87 \%$ of the total genetic variance for insemination outcome on the liability scale when $t=110 \mathrm{~d}$. The third parameter $\left(g_{22}\right)$ explained only $1 \%$ of the total variance (at $t=110 \mathrm{~d}$ ), indicating its limited effect on the ability to predict a cow's pregnancy status after insemination.

Estimated genetic correlations between the 3 random coefficients using Model 1 (Table 2) indicated moderate to low negative correlations among $a_{1}, a_{0}$, and $a_{2}$. However, the genetic correlation between $a_{0}$ and $a_{2}$ was positive and large in magnitude. These correlations in-

Table 2. Posterior means (above the diagonal) and standard deviations (below the diagonal) for genetic correlations between random coefficients using Model 1

\begin{tabular}{lllr}
\hline $\begin{array}{l}\text { Random } \\
\text { coefficient }\end{array}$ & $a_{0}$ & $a_{1}$ & \multicolumn{1}{c}{$a_{2}$} \\
\hline$a_{0}$ & & -0.4592 & 0.8479 \\
$a_{1}$ & 0.2097 & & -0.2357 \\
$a_{2}$ & 0.0671 & 0.1722 & \\
\hline
\end{tabular}

dicate that, for low to moderate values of $t$ (days between calving and insemination), the second parameter $\left(a_{1}\right)$ of the function plays a role in decreasing the genetic variance for insemination outcomes on the liability scale as a result of its negative correlation with the intercept $\left(a_{0}\right)$ and the limited effect of the third parameter $\left(a_{2}\right)$ with the corresponding covariable, $(t / 365)^{2}$, for low to moderate values of $t$. For large values of $t$, the contribution of the third parameter increases and offsets the decrease induced by the negative correlation between the first and second parameters. This trend is evident in Table 3.

Posterior means of the genetic variance for insemination outcomes at specific time points, as well as the genetic correlations between time points, are presented in Table 3 . The genetic variance decreased continuously from $70 \mathrm{~d}$ to approximately $150 \mathrm{~d}$ after calving and then increased with time. The change over time in heritability of an insemination outcome (Figure 1a) shows the same trend as observed for the genetic variance, such that heritability decreased at the beginning of the lactation to a minimum (0.032) between 155 and $176 \mathrm{~d}$ and then increased continuously to the end of lactation. However, the range of variation in heritability estimates over time was small, from 0.032 to 0.041 , with an average of 0.034 . Although higher than the estimate obtained using a repeatability model (Averill et al., 2004), the latter was still within the range of estimates reported in the literature (Bar-Anan et al., 1985; Raheja et al., 1989). The genetic correlations for insemination outcomes at different time points (Table 3 ) were positive and high, ranging from 0.787 to 0.998 . The magnitude of these correlations decreased with an increase in time. In fact, the correlation was 0.998 between 70 and 100 $\mathrm{d}$ and decreased to 0.787 between 70 and $365 \mathrm{~d}$. This result suggests that, if a cow fails to get pregnant in a given insemination, her chance of becoming pregnant decreases with an increase in the interval between the failed insemination and consecutive inseminations. Furthermore, these correlations must be interpreted with caution, given that cows becoming pregnant in a given insemination have all their "hypothetical" future inseminations assumed by the model as if they were successful. In other words, for these pregnant cows, the genetic correlation between "hypothetical" future inseminations is equal to one. Consequently, the true genetic correlation between an unsuccessful insemination and a future insemination is smaller than the values presented in Table 3.

The point estimate of the service sire variance $(0.010)$ was slightly higher than that obtained using the repeatability model (0.009) of Averill et al. (2004) but was within the range of estimates reported for male fertility (Hansen et al., 1983; Taylor et al., 1985; Ranberg et 
Table 3. Posterior means of genetic variances (SD) in insemination outcome (boldfaced, on the diagonal), and means (above the diagonal) and standard deviations (below the diagonal) for genetic correlations between specific time points using Model 1

\begin{tabular}{|c|c|c|c|c|c|c|}
\hline Time points, $\mathrm{d}$ & 70 & 100 & 150 & 250 & 300 & 365 \\
\hline 70 & $\begin{array}{c}0.0371 \\
(0.0039)\end{array}$ & 0.9977 & 0.9824 & 0.9097 & 0.8582 & 0.7867 \\
\hline 100 & 0.0005 & $\begin{array}{c}0.0359 \\
(\mathbf{0 . 0 0 4 2})\end{array}$ & 0.9929 & 0.9358 & 0.8909 & 0.8264 \\
\hline 150 & 0.0048 & 0.0022 & $\begin{array}{c}\mathbf{0 . 0 3 5 0} \\
(\mathbf{0 . 0 0 5 4})\end{array}$ & 0.9710 & 0.9383 & 0.8868 \\
\hline 250 & 0.0317 & 0.0246 & 0.0126 & $\begin{array}{c}0.0374 \\
(0.0086)\end{array}$ & 0.9937 & 0.9713 \\
\hline 300 & 0.0530 & 0.0441 & 0.0279 & 0.0032 & $\begin{array}{c}0.0408 \\
(0.0104)\end{array}$ & 0.9918 \\
\hline 365 & 0.0828 & 0.0724 & 0.0521 & 0.0148 & 0.0043 & $\begin{array}{c}0.0474 \\
(0.0128)\end{array}$ \\
\hline
\end{tabular}

al., 2003). The permanent environmental variance was substantially smaller $(0.05)$ than the estimate obtained by Averill et al. (2004) using the repeatability model (0.17). The new estimate seems more realistic, perhaps indicating better modeling using a random regression model that accounts for the variation in genetic variance over time.

\section{Model 2}

Table 4 presents a summary of the posterior distributions of the genetic (co)variance, the permanent environmental variance, and the service sire variance using Model 2. As with Model 1, the intercept explained a large portion of the total variance. Estimated genetic correlations (Table 5) for the fourth $\left(a_{3}\right)$ and fifth $\left(a_{4}\right)$ parameters with the other $3\left(a_{0}, a_{1}, a_{2}\right)$ parameters were negative except for the correlation between the fourth and second $a_{1}$ parameters $(0.11)$. All of the genetic corre- lations among the first 3 parameters and between the fourth and fifth parameters were positive and ranged from 0.12 (first with second) to 0.60 (fourth and fifth). Although a detailed dissection of the effect of each parameter on the genetic variance of insemination success is more complex and less evident than with Model 1, in general it seems that the fourth and fifth parameters had a more pronounced effect on genetic variance at the beginning of lactation as result of their negative correlation with the intercept and the magnitude of the covariables $\log (365 / t)$ and $\log (365 / t)^{2}$ for small values of $t$. As soon as $t$ reached a value of $90 \mathrm{~d}$, the contribution of the second and third parameters (positively correlated with the intercept) exceeded the decrease induced by the fourth and fifth parameters, and the genetic variance of the insemination outcome increased sharply. The point estimate of the service sire variance was similar to that obtained using Model 1 (0.01) and that obtained by Averill et al. (2004) using a repeatabil-
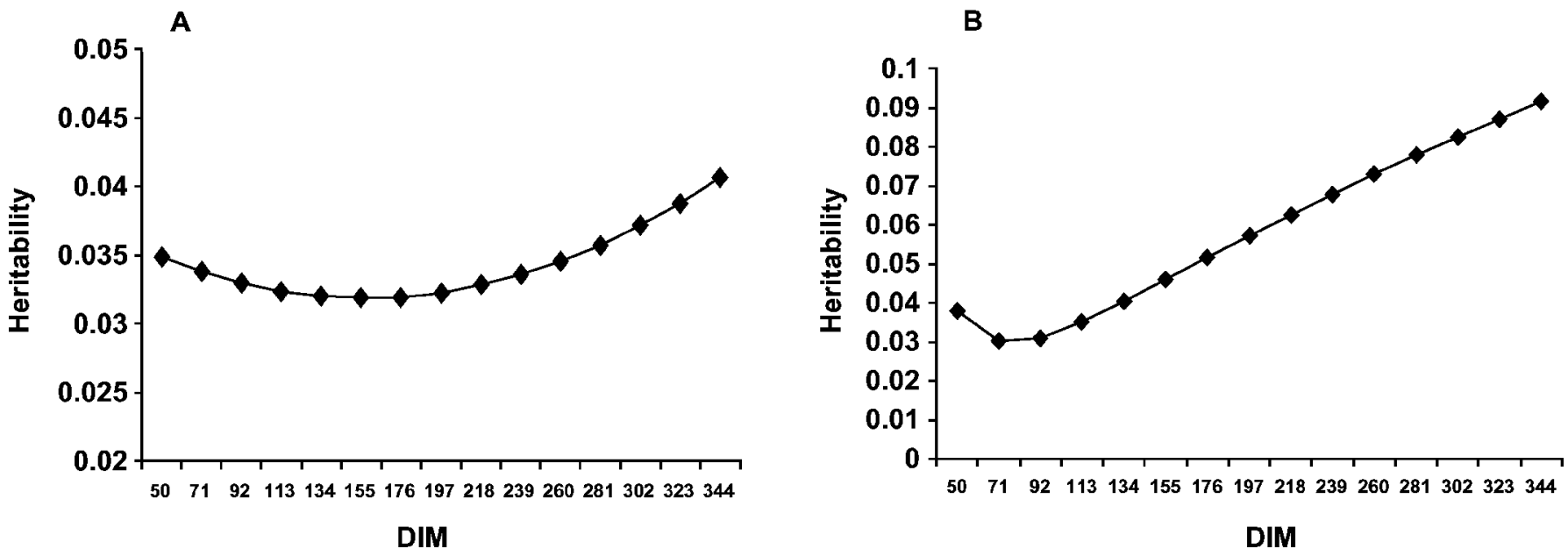

Figure 1. Heritability of insemination outcome as a function of time (a) using Model 1 and (b) using Model 2. 
Table 4. Summary of the posterior distributions for genetic (co)variances among the 5 random coefficients, permanent environmental variance, and service sire variance using Model 2

\begin{tabular}{lrlrr}
\hline Component $^{1}$ & \multicolumn{1}{l}{ Mean } & \multicolumn{2}{c}{ SD } & \multicolumn{2}{c}{ HPD, 95\% } \\
\hline$g_{00}$ & 0.0970 & 0.0175 & 0.0627 & 0.1174 \\
$g_{11}$ & 0.0011 & 0.0002 & 0.0007 & 0.0013 \\
$g_{22}$ & 0.0007 & $4.5 \mathrm{E}-5$ & 0.0006 & 0.0008 \\
$g_{33}$ & 0.0207 & 0.0061 & 0.0097 & 0.0283 \\
$g_{44}$ & 0.0008 & $9.2 \mathrm{E}-5$ & 0.0007 & 0.0010 \\
$g_{01}$ & 0.0009 & 0.0037 & -0.0048 & 0.0048 \\
$g_{02}$ & 0.0041 & 0.0012 & 0.0023 & 0.0055 \\
$g_{03}$ & -0.0342 & 0.0162 & -0.0507 & -0.0017 \\
$g_{04}$ & -0.0070 & 0.0007 & -0.0081 & -0.0055 \\
$g_{12}$ & 0.0003 & 0.0002 & -0.0002 & 0.0007 \\
$g_{13}$ & 0.0007 & 0.0016 & -0.0013 & 0.0031 \\
$g_{14}$ & $-7.1 \mathrm{E}-5$ & 0.0002 & -0.0004 & 0.0004 \\
$g_{23}$ & -0.0012 & 0.0008 & -0.0023 & 0.0002 \\
$g_{24}$ & $-3.3 \mathrm{E}-5$ & $6.6 \mathrm{E}-5$ & -0.0001 & 0.0001 \\
$g_{34}$ & 0.0025 & 0.0012 & $-9.0 \mathrm{E}-6$ & 0.0038 \\
$\sigma_{p}^{2}$ & 0.0212 & 0.0086 & 0.0080 & 0.0376 \\
$\sigma_{s}^{2}$ & 0.0101 & 0.0012 & 0.0077 & 0.0125 \\
\hline
\end{tabular}

${ }^{1} g_{i j}$ is the genetic (co)variance between random coefficients $i$ and $j ; \sigma_{s}^{2}$ is the service sire variance; and $\sigma_{p}^{2}$ is the permanent environment variance.

ity model (0.009). However, the variance of the permanent environment was smaller (0.02) than the estimate obtained using Model 1 (0.05) or using the repeatability model (0.17) of Averill et al. (2004).

Changes in heritability over time are presented in Figure 1b. Similar to the genetic variance, the heritability decreased to a minimum at approximately $90 \mathrm{~d}$ and then increased continuously to reach estimates greater than 0.08 by $300 \mathrm{~d}$. The average estimate of heritability was much higher than those obtained using Model 1 (0.034) or the repeatability model (0.028) using the same data set with different editing criteria (Averill et al., 2004).

The genetic correlations for insemination outcome at different time points (Table 6) were positive but of smaller magnitude than those obtained using Model 1. As with Model 1, the magnitudes of these correlations decreased with an increase in the interval between inseminations. For 2 inseminations realized at an interval of less than $100 \mathrm{~d}$, the genetic correlation was always greater than 0.90, except between 70 and $150 \mathrm{~d}$ (Table
6). However, the decrease in the magnitude of the genetic correlation with an increase in the interval between inseminations was more pronounced than with Model 1 (Table 3). In fact, the correlation using Model 2 (Model 1) was 0.903 (0.998) between $t=70$ and $t=$ 100 and declined to 0.437 (0.787) between $t=70$ and $t=365$.

\section{Model Selection Criteria}

The Bayes factor was equal to 5.8 in favor of Model 1 , indicating that Model 1 was more plausible than Model 2, given the data. This result suggests that Model 2 included too many parameters to fit a data set with a limited number of records per cow. In fact, the average number of records per cow was 1.76 , with $36 \%$ of cows having only one record. Furthermore, this result helps explain the unexpected estimates of heritabilities, genetic correlations between insemination events, and permanent environmental variance. It should be noted that holding the permanent effect variance constant over time could be part of the problem, because this has been the case in analyzing milk yield data using test-day models. However, increasing the number of parameters by including random regression coefficients to model the permanent effect could be counterproductive, given the limited number of records per cow in the data set used in this study.

The ranking of animals based on 3 new selection criteria provided extra tools for selection. Table 7 presents the top and bottom 5 cows based on the 3 defined probabilities using Model 1 . The 5 best cows had a high probability of conception after first insemination and consequently low probabilities for not being pregnant after 3 inseminations or after $365 \mathrm{~d}$. In fact, all 5 cows became pregnant on their first insemination. The worst 5 cows had a low probability of conception after the first insemination and high $p_{2}$ and $p_{3}$. Based on their phenotypic data, all 5 cows were open after more than $300 \mathrm{~d}$ since calving.

\section{CONCLUSIONS}

The use of longitudinal models allows for the inclusion of all breeding information over a specific period. It

Table 5. Posterior means (above the diagonal) and standard deviations (below the diagonal) for genetic correlations between random coefficients using Model 2

\begin{tabular}{|c|c|c|c|c|c|}
\hline $\begin{array}{l}\text { Random } \\
\text { coefficient }\end{array}$ & $a_{0}$ & $a_{1}$ & $a_{2}$ & $a_{3}$ & $a_{4}$ \\
\hline$a_{0}$ & & 0.1176 & 0.4993 & -0.7073 & -0.7947 \\
\hline$a_{1}$ & 0.3662 & & 0.3013 & 0.1145 & -0.0715 \\
\hline$a_{2}$ & 0.1042 & 0.2841 & & -0.3047 & -0.0474 \\
\hline$a_{3}$ & 0.2646 & 0.3119 & 0.1871 & & 0.5969 \\
\hline$a_{4}$ & 0.022 & 0.2532 & 0.0909 & 0.2581 & \\
\hline
\end{tabular}


Table 6. Posterior means of genetic variances (SD) of insemination outcome (boldfaced, on the diagonal), and means (above the diagonal) and standard deviations (below the diagonal) for genetic correlations between specific time points using Model 2

\begin{tabular}{|c|c|c|c|c|c|c|}
\hline $\begin{array}{l}\text { Time } \\
\text { points, } \mathrm{d}\end{array}$ & 70 & 100 & 150 & 250 & 300 & 365 \\
\hline 70 & $\begin{array}{c}0.0321 \\
(0.0128)\end{array}$ & 0.9028 & 0.7043 & 0.5211 & 0.4758 & 0.4366 \\
\hline 100 & 0.04662 & $\begin{array}{c}0.0343 \\
(0.0122)\end{array}$ & 0.9397 & 0.8318 & 0.8001 & 0.7707 \\
\hline 150 & 0.1239 & 0.0224 & $\begin{array}{c}0.0481 \\
(0.0079)\end{array}$ & 0.9704 & 0.9549 & 0.9382 \\
\hline 250 & 0.1612 & 0.0440 & 0.0045 & $\begin{array}{c}0.0782 \\
(0.0056)\end{array}$ & 0.9982 & 0.9933 \\
\hline 300 & 0.1626 & 0.0454 & 0.0065 & 0.0006 & $\begin{array}{c}0.0921 \\
(0.0097)\end{array}$ & 0.9984 \\
\hline 365 & 0.1597 & 0.0440 & 0.0099 & 0.0026 & 0.0008 & $\begin{array}{c}0.1093 \\
(0.0152)\end{array}$ \\
\hline
\end{tabular}

avoids eliminating useful information and makes joint analysis of male and female fertility possible. Longitudinal models account for all service sires as well as the order in which they were used, potentially leading to more precise estimates. In this study, 2 random regression models with different parameter functions, a quadratic linear model (Model 1) and the Ali-Schaeffer model (Model 2), were implemented and compared. Estimates of genetic parameters from the 2 models studied herein indicate the possibility that reproductive performance can be genetically improved through selection. Furthermore, random regression models accounted for the variation in genetic variance for insemination outcomes over time, potentially leading to more realistic modeling compared with a repeatability model. Estimates of genetic parameters were quite different between the 2 random regression models. Estimates of heritability using Model 2 were higher than those ex-

Table 7. Probability of conception after the first insemination, probability of no conception after 3 inseminations, and probability of no conception after $365 \mathrm{~d}$ for the best and worst 5 cows using Model 1

\begin{tabular}{lllll}
\hline Cow & $p_{1}^{1}$ & $p_{2}^{2}$ & $p_{3}^{3}$ & $\begin{array}{l}\text { Successful } \\
\text { insemination }\end{array}$ \\
\hline Best 5 cows & & & & \\
1 & 0.543 & 0.069 & $<0.01$ & 1 \\
2 & 0.539 & 0.070 & $<0.01$ & 1 \\
3 & 0.532 & 0.070 & $<0.01$ & 1 \\
4 & 0.528 & 0.071 & $<0.01$ & 1 \\
5 & 0.522 & 0.073 & $<0.01$ & 1 \\
Worst 5 cows & & & & \\
1 & 0.177 & 0.614 & 0.302 & Open \\
2 & 0.180 & 0.606 & 0.298 & Open \\
3 & 0.184 & 0.603 & 0.297 & Open \\
4 & 0.186 & 0.603 & 0.296 & Open \\
5 & 0.189 & 0.601 & 0.296 & Open \\
\hline
\end{tabular}

${ }^{1}$ Probability of conception after the first insemination $\left(t_{j}=75 \mathrm{~d}\right)$.

${ }^{2}$ Probability of no conception in the first 3 inseminations $\left(t_{j}=75\right.$ $\left.\mathrm{d}, t_{j}=96 \mathrm{~d}, t_{j}=117 \mathrm{~d}\right)$.

${ }^{3}$ Probability of no conception within $365 \mathrm{~d}$. pected for fertility traits, especially by the end of the lactation. Comparison of the 2 models based on the Bayes factor indicated that Model 1 was more plausible, given the data. In this study, the permanent effect was assumed to be constant, and potential selection bias resulting from the culling of a heifer because of fertility problems was not considered because of limited information available in the data set. With a more complete data set, a longitudinal multiple-trait model for different lactations with varying permanent effects would be theoretically more appropriate. However, implementation of this model may be challenging for large data sets.

\section{ACKNOWLEDGMENTS}

We are grateful to 2 anonymous referees whose comments significantly improved the revised version of this manuscript.

\section{REFERENCES}

Albert, J. H., and S. Chib. 1993. Bayesian analysis of binary and polychotomous response data. J. Am. Stat. Assoc. 88:669-679.

Ali, T., and L. R. Schaeffer. 1987. Accounting for covariances among test day milk yields in dairy cows. Can. J. Anim. Sci. 67:637-644.

Averill, T., R. Rekaya, and K. Weigel. 2004. Genetic analysis of male and female fertility using longitudinal binary data. J. Dairy Sci. 87:3947-3952.

Bar-Anan, R., M. Ron, and G. R. Wiggans. 1985. Associations among milk yield, yield persistency, conception, and culling of Israeli Holstein dairy cattle. J. Dairy Sci. 68:382-386.

Beam, S. W., and W. R. Butler. 1999. Energy balance effects on follicular development and first ovulation in post-partum cows. J. Reprod. Fertil. 54:411-424.

Butler, W. R., and R. D. Smith. 1989. Interrelationships between energy balance and postpartum reproductive function in dairy cattle. J. Dairy Sci. 72:767-783.

Freeman, A. E. 1984. Secondary traits: Sire evaluation and the reproductive complex. J. Dairy Sci. 67:449-458.

Hansen, L. B., A. E. Freeman, and P. J. Berger. 1983. Variances, repeatabilities, and age adjustments of yield and fertility in dairy cattle. J. Dairy Sci. 66:281-292.

Heringstad, B., R. Rekaya, D. Gianola, G. Klemetsdal, and K. A. Weigel. 2001. Bayesian analysis of liability to clinical mastitis in 
Norwegian cattle with a threshold model: Effects of data sampling method and model specification. J. Dairy Sci. 84:2337-2346.

Heringstad, B., R. Rekaya, D. Gianola, G. Klemetsdal, and K. A. Weigel. 2003. Genetic change for clinical mastitis in Norwegian cattle: A threshold model analysis. J. Dairy Sci. 86:369-375.

Huisman, A. E., E. Kanis, and J. A. M. van Arendonk. 2002. Application of random regression models in pig breeding to select on growth and feed intake patterns. Pages 1-8 in 53rd Annu. Mtg. EAAP.

Jakobsen, J. H., R. Rekaya, J. Jensen, D. A. Sorensen, P. Madsen, D. Gianola, L. G. Christensen, and J. Pederson. 2003. Bayesian estimates of covariance components between lactation curve parameters and disease liability in Danish Holstein cows. J. Dairy Sci. 86:3000-3007.

Jamrozik, J., J. Fatehi, G. J. Kistemaker, and L. R. Schaeffer. 2005. Estimates of genetic parameters for Canadian Holstein female reproduction traits. J. Dairy Sci. 88:2199-2208.

Jensen, J. 2001. Genetic evaluation of dairy cattle using test-day models. J. Dairy Sci. 84:2803-2812.

Kadarmideen, H., R. Rekaya, and D. Gianola. 2001. Bayesian approach to cross-sectional genetic analysis of mastitis in dairy cattle. J. Anim. Sci. 73:229-240.

Kadarmideen, H. N., R. Thompson, and G. Simm. 2000. Linear and threshold model genetic parameters for disease, fertility and milk production in dairy cattle. Anim. Sci. 71:411-419.

Kirkpatrick, M., and N. Heckman. 1989. A quantitative genetic model for growth, shape, reaction norms and other infinite-dimensional characters. J. Math. Biol. 27:429-450.

Marti, C. F., and D. A. Funk. 1994. Relationship between production and days open at different levels of herd production. J. Dairy Sci. 77:1682-1690.

Meyer, K. 1998. Estimating covariance functions for longitudinal data using a random regression model. Genet. Sel. Evol. 30:221-240.

Newton, M. A., and A. E. Raftery. 1994. Approximate Bayesian inference with the weighted likelihood bootstrap. J. R. Stat. Soc. B $56: 3-48$.
Pool, M. H., L. L. G. Janss, and T. H. E. Meusissen. 2000. Genetic parameters of Legendre polynomials for first parity lactation curves. J. Dairy Sci. 83:2640-2649.

Raheja, K. L., E. B. Burnside, and L. R. Schaeffer. 1989. Heifer fertility and its relationship with cow fertility and production traits in Holstein dairy cattle. J. Dairy Sci. 72:2665-2669.

Ranberg, M. A., I. B. Heringstad, G. Klemetsdal, M. Svendsen, and T. Steine. 2003. Heifer fertility in Norwegian dairy cattle: Variance components and genetic change. J. Dairy Sci. 86:2706-2714.

Rekaya, R., D. Gianola, K. Weigel, and G. Shook. 2003. Longitudinal random effects models for genetic analysis of binary data with application to mastitis in dairy cattle. Genet. Sel. Evol. 35:1-12.

Rekaya, R., S. L. Rodriguez-Zas, D. Gianola, and G. E. Shook. 1998. Test-day models for longitudinal binary responses: An application to mastitis in Holsteins. Page 44 in Book of Abstracts, 49th Annu. Mtg. EAAP. Wageningen Pers, Wageningen, the Netherlands.

Royal, M. D., A. O. Darwash, A. P. E. Flint, R. Webb, J. A. Woolliams, and G. E. Lamming. 2000. Declining fertility in dairy cattle: Changes in traditional and endocrine parameters of fertility. Anim. Sci. 70:487-501.

Sorensen, D. A., S. Anderson, D. Gianola, and I. Korsgaard. 1995. Bayesian inference in threshold models using Gibbs sampling. Genet. Sel. Evol. 27:229-249.

Swalve, H. H. 2000. Theoretical basis and computational methods for different test-day genetic evaluation methods. J. Dairy Sci. 83:1115-1124.

Taylor, J. F., R. W. Everett, and B. Bean. 1985. Systematic environmental, direct, and service sire effects on conception rate in artificially inseminated Holstein cows. J. Dairy Sci. 68:3004-3022.

Veerkamp, R. F., S. Brotherstone, B. Engel, and T. H. E. Meuwissen. 2001. Analysis of censored survival data using random regression models. Anim. Sci. 72:1-10.

Veerkamp, R. F., and M. E. Goddard. 1998. Covariance functions across herd production levels for test day records on milk, fat, and protein yields. J. Dairy Sci. 81:1690-1701.

White, I. M. S., R. Thompson, and S. Brotherstone. 1999. Genetic and environmental smoothing of lactation curves with cubic splines. J. Dairy Sci. 82:632-638. 